\title{
Effect of social instigation and aggressive behavior on hormone levels of lactating dams and adult male Wistar rats
}

\author{
Caroline Perinazzo da Veiga ${ }^{1}$; Bruno Carlo Cerpa Aranda ${ }^{1}$, Dirson Stein ${ }^{1}$, Celso Rodrigues \\ Franci $^{2}$, Klaus A. Miczek ${ }^{3}$, Aldo Bolten Lucion ${ }^{1}$ and Rosa Maria Martins de Almeida ${ }^{1}$ \\ 1 - Universidade Federal do Rio Grande do Sul, Porto Alegre, RS, Brazil \\ 2 - Universidade de São Paulo, Ribeirão Preto, SP, Brazil \\ 3 - Tufts University, Medford, MA, USA
}

\begin{abstract}
Among rodents, maternal aggression in the postpartum period represents a species-typical adaptation, but when aggressive behavior increases beyond this adaptive level, it can represent a model of excessive aggression. This study assessed the neuroendocrine response of lactating rats and socially instigated male rats. The aim of the present study was to assess neuroendocrine responses and the behavioral pattern of lactating rats and males that were subjected to an emotional stressor using the social instigation protocol. We measured plasma corticosterone levels as the key hormonal parameter of the hypothalamic-pituitary-adrenal (HPA) axis and oxytocin, prolactin, and progesterone, which are released in response to several types of stressors. Our results showed that lactating rats that were subjected to only social instigation or aggressive confrontation in the presence of their pups had lower plasma corticosterone levels, and this response was similar to oxytocin, prolactin, and progesterone levels. By contrast, male rats showed increased corticosterone levels after being subjected only to social instigation. Male rats also engaged in aggressive behavior compared with the control group. In conclusion, this study demonstrated that lactating rats subjected to social instigation exhibited an attenuation of the HPA axis response, which is considered to be crucial to the dam's welfare so that it can care for its offspring. Thus, we can infer that lactation is a relevant factor in neuroendocrine responses to stress because of the increased levels of corticosterone in males. Keywords: social instigation, lactating rats, corticosterone, male, HPA axis
\end{abstract}

Received 12 February 2011; received in revised form 27 May 2011; accepted 6 June 2011. Available on line 18 June 2011

\section{Introduction}

The postpartum period constitutes a complex suite of physiological and behavioral processes that are important to offspring growth and development (Lonstein, 2005). Maternal aggression is observed during lactation and serves to protect the pups and defend their territory against intruders (Erskine, Barfield, \& Goldman, 1978; Lonstein \& Gammie, 2002; Numan \& Insel, 2003; Lonstein, 2005). In rats, maternal aggressive behavior is more frequent between postpartum days (PPD) 3 and 12, on which dams show

Caroline Perinazzo da Veiga, Dirson Stein, Programa de Pós-Graduação em Neurociências, Instituto de Ciências Básicas da Saúde, Universidade Federal do Rio Grande do Sul, Porto Alegre, RS, Brazil. Bruno Carlo Cerpa Aranda, Programa de Pós-Graduação em Fisiologia, Instituto de Ciências Básicas da Saúde, Universidade Federal do Rio Grande do Sul, Porto Alegre, RS, Brazil. Celso Rodrigues Franci, Departamento de Fisiologia, Faculdade de Medicina de Ribeirão Preto, Universidade de São Paulo, Brazil. Klaus A. Miczek, Departments of Psychology, Pharmacology, Neuroscience and Psychiatry, Tufts University, Medford and Boston, USA. Aldo Bolten Lucion, Departamento de Fisiologia, Programa de Pós-Graduação em Neurociências, intense caring for their young (Consiglio \& Bridges, 2009; Erskine et al., 1978). Among rodents, maternal aggression in the postpartum period represents a species-typical adaptation, but when aggressiveness increases beyond this period, this can represent a model of excessive aggression, bearing a resemblance to a clinical pattern. Therefore, dams in the postpartum period can be used as a model of naturally increased aggression associated with social instigation (Veiga, Miczek, Lucion, \& De Almeida, 2011).

Social instigation is an experimental protocol used to heighten species-typical aggressive behaviors (Veiga,

Instituto de Ciências Básicas da Saúde, Universidade Federal do Rio Grande do Sul, Porto Alegre, RS, Brazil. Rosa Maria Martins de Almeida, Laboratório de Psicologia Experimental, Neurociências e Comportamento. Instituto de Psicologia do Desenvolvimento e da Personalidade, da Universidade Federal do Rio Grande do Sul (UFRGS), Porto Alegre, RS, Brazil. Correspondence regarding this article should be directed to: Rosa Maria Martins de Almeida, Instituto de Psicologia - Universidade Federal do Rio Grande do Sul Rua Ramiro Barcelos, 2600, Bairro Santa Cecília, Porto Alegre, RS 90035-003, Brasil. Phone: +55 (51) 3308-5066. Fax: +55 (51) 3308-5470. E-mail: rosa_almeida@yahoo.com or rosa.almeida@ufrgs.br 
Miczek, Lucion, \& De Almeida, 2007; Veiga et al., 2011). This procedure is highly effective in increasing aggressive behavior in animals by instigating the resident with its proximity to an opponent (Potegal, 1991). The exposure of an experimental subject to a potential rival for a short time prior to the actual confrontation engenders intense levels of aggression, which was originally described in mice (Lagerspetz \& Hautojarvi, 1967). Mice, rats, and hamsters perform attacks with a very low latency and high frequency when provoked by an intruder in their home cage or in an unfamiliar place, after having been previously provoked by an opponent (De Almeida \& Miczek, 2002; Fish, Faccidomo, \& Miczek, 1999; Potegal, 1991). Even after removal of the instigating stimulus, high levels of aggression persist in fish and rodents, presumably from increased "aggressive arousal" or "attack readiness" (Potegal, 1991). Social instigation specifically increases aggressive behavior and does not activate locomotion, feeding, or sexual behavior (Lagerspetz \& Huatojarvi, 1967; Potegal \& Tenbrink, 1984; Potegal, 1991). A recent study conducted by Veiga et al. (2011) showed that lactating rats significantly increase their aggressiveness when subjected to social instigation. One of the advantages of using social instigation is that it engenders basal levels of aggression, facilitating the use of some compounds to assess their effects on aggression.

Endocrine and behavioral responses of mothers to a threatening stimulus change during lactation (Agrati, Zuluaga, Fernández-Guasti, Meikle, \& Ferreira, 2008). The stress-responsive neuroendocrine system, known as the hypothalamic-pituitary-adrenal (HPA) axis, helps maintain and adapt the body to any disturbance in homeostasis and is essential to support the body's physiological functions (Kudielka \& Kirschbaum, 2005). Under stress, the paraventricular nucleus of the hypothalamus, more specifically the parvocellular paraventricular nucleus ( $\mathrm{pPVN})$, secretes corticotropin-releasing hormone $(\mathrm{CRH})$ and produces vasopressin (Brunton, Russell, \& Douglas, 2008). $\mathrm{CRH}$ secretion leads to the release of the anterior pituitary adrenocorticotropic hormone (ACTH) and this hormone, in turn, increases the synthesis and secretion of glucocorticoids from the adrenal cortex (Kudielka \& Kirschbaum, 2005).

Lactating rats show an attenuated HPA axis response to a wide variety of emotional stressors, such as the elevated plus maze, noise stress, and social stress, and physical stressors, such as exposure to ether, footshock, forced swimming, hypertonic saline injection, and liposaccharide injection (Thoman, Conner, \& Levine, 1970; Stern \& Levine, 1972; Stern, Goldman, \& Levine, 1973; Myers, Denenberg, Thoman, Holloway, \& Bowerman, 1975; Lescoat \& Maniey, 1976; Smotherman, Wiener, Mendoza, \& Levine, 1976; Lightman \& Young, 1987, 1989; Walker, Lightman,
Steele, \& Dallman, 1992; Walker, Trottier, Rochford, \& Lavallee, 1995; Windle et al., 1997; Neumann et al., 1998; Lightman, Windle, Wood, Kershaw, \& Shanks, 2001; Neumann, Toschi, Ohl, Torner, \& Kromer, 2001). Some studies have sought to elucidate the possible causes of an attenuated HPA axis response to some stressful situations in lactating rats (Da Costa, Wood, Ingram, \& Lightman, 1996; Toufexis \& Walker, 1996; Douglas et al., 1998; Johnstone et al., 2000; Neumann et al., 2001). Adult males have lower basal corticosterone levels than lactating dams (Koolhaas, Meerlo, De Boer, Strubbe, \& Bohus, 1997), and when subjected to stressful situations, such as the resident-intruder test, social isolation, and restraint stress, male rats show an increase in corticosterone secretion (Gamallo, Villanua, Trancho, \& Fraile, 1986; Haller, Barna, \& Baranyi, 1995; Hucklebridge \& Nowell, 1974; Koolhaas et al., 1997; Li et al., 2010; Miczek, Nikulina, Kream, Carter, \& Espejo, 1999; Veenema, Torner, Blume, Beiderbeck, \& Neumann, 2007; Wotjak et al., 1996; Zayan, 1991).

Several studies have furthered our understanding about the hormonal (Albert, Jonik, \& Walsh, 1992; Mayer \& Rosenblatt, 1987; Mayer, Monroy, \& Rosenblatt, 1990) and neurobiological bases (Consiglio \& Lucion, 1996; Factor, Mayer, \& Rosenblatt, 1990; Ferreira, Dahlof, \& Hansen, 1987; Hansen, 1989; Kolunie \& Stern, 1995; Lonstein, Simmons, \& Stern, 1998) of aggressive behavior in lactating rats, but the neuroendocrine responses of lactating resident rats have not been extensively investigated (Neumann et al., 2001). The aim of the present study was to assess neuroendocrine responses and the behavioral pattern of lactating rats subjected to an emotional stressor using the social instigation protocol. Specifically, we assessed plasma corticosterone levels as the main hormonal parameter of the HPA axis and oxytocin, prolactin, and progesterone, which are released in response to several types of stressors. Thereafter, the same parameters mentioned above were assessed in adult male rats subjected to social instigation.

\section{Materials and methods}

\section{Animals}

For the experiments, we used primiparous Wistar rats and adult male Wistar rats aged approximately 90 days from the Universidade do Vale do Rio dos Sinos (UNISINOS), southern Brazil. The animals were kept under controlled temperature $\left(21 \pm 1^{\circ} \mathrm{C}\right)$ and light $(12$ $\mathrm{h} / 12 \mathrm{~h} \mathrm{light/dark} \mathrm{cycle,} \mathrm{lights} \mathrm{off} \mathrm{at} \mathrm{3:00} \mathrm{PM).} \mathrm{Each}$ female was individually housed in transparent acrylic boxes that measured $46 \mathrm{~cm} \mathrm{x} 31 \mathrm{~cm} \mathrm{x} 17 \mathrm{~cm}$ and received food and water ad libitum. The delivery date was controlled, and the day of birth of the pups was set as PPD 0. On PPD 1, the pups were standardized to eight per litter, regardless of sex. To test the aggressive 
behavior of lactating rats, intruder males (Intr) were used, which weighed approximately $50 \mathrm{~g}$ less than the females. Stimulus males (SMs) were also used, which were protected by an acrylic tube and did not have direct contact with the residents. Intr and SM rats were maintained in groups of five per box. Inst rats were never used as SMs. The hormones from these males were assessed after social instigation. The males that had their plasma hormonal levels analyzed after social instigation and aggressive behavior against intruder males were adult rats kept in individual acrylic home cages of the same size described above, together with an adult female for 14 days. To test the aggressive behavior of adult male rats, intruder males were also used, which weighed approximately $30 \mathrm{~g}$ less than the residents. The SMs were approximately $50 \mathrm{~g}$ smaller than the resident animals. The experiments were performed in compliance with the standards of the Brazilian College of Animal Experimentation (COBEA) and were approved by the Research Ethics Committee of this institution.

\section{Confrontation between resident and intruder male rats}

On PPD 3, female rats were selected for aggressive behavior, and only those that bit the intruder more than twice during $10 \mathrm{~min}$ of confrontation were used for the experiment. The behavioral test was performed in the resident female's box in the presence of pups at the beginning of the dark period. From PPD 3 to 12, a high level of aggressive behavior was observed among females, but after this period, aggressive behavior began to attenuate (Erskine et al., 1978; Mos \& Olivier, 1986).

The resident males were not previously selected for aggressive behavior because the aim of the present study was to assess their hormonal response after social instigation and aggressive confrontation.

\section{Social instigation}

\section{Female rats}

The social instigation procedure was performed on PPD 5 (Figure 1). Social instigation consists of placing an acrylic tube with holes $(28 \mathrm{~cm}$ length, $10 \mathrm{~cm}$ diameter) that contains an opponent (stimulus) male or instigator (Figure 1) for $5 \mathrm{~min}$ in the resident female's box. Residents typically threaten the protected stimulus male and attack the perforated cylindrical tube. Rodents generally perform attacks at a very high frequency and low latency when confronted with an intruder in their boxes after having been previously instigated by an opponent (Potegal, 1991). The pups remained in the box with their mothers during social instigation.

\section{Male rats}

After 14 days of adaptation in the animal facility, adult male rats, approximately 74 days of age, were

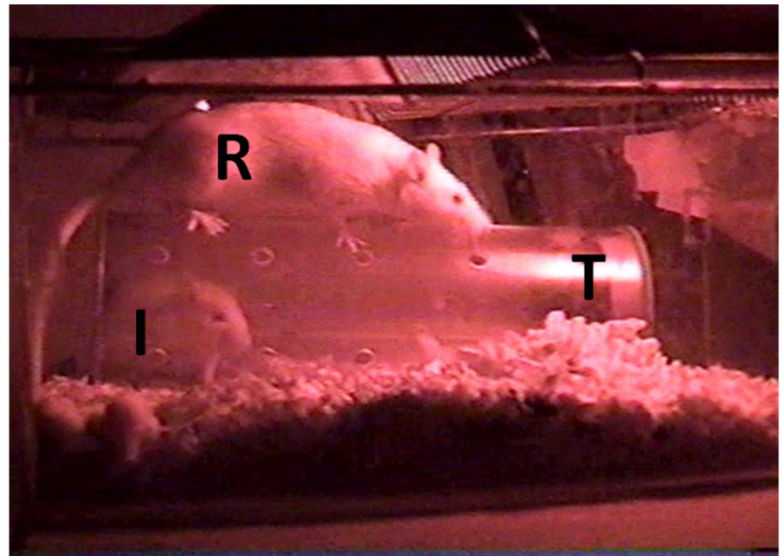

Figure 1. Resident $(\mathrm{R})$ lactating rat and stimulus rat or instigator (I) in the acrylic tube (T) during social instigation in the resident's box on postpartum day 5 in the presence of pups.

subjected to social instigation. The females that were initially placed with the male were kept in the home cage until the beginning of social instigation, and then the females were placed in another cage. Social instigation was performed following the previously described protocols for female rats.

\section{Maternal aggressive behavior}

On PPD 5, 5 min after the end of social instigation, maternal aggressive behavior against a male intruder was tested for $10 \mathrm{~min}$. The behavioral repertoire previously defined by De Almeida and Lucion (1997) included the frequency of aggressive behaviors: lateral attack, biting, and dominance. In the presence of the intruder, the duration of non-aggressive behaviors, such as investigating the intruder, self-grooming, raising the forepaws, interacting with the pups, and walking, were also recorded. Social instigation and maternal aggressive behavior were filmed and later analyzed by an examiner using Observer software (version 3.0, Noldus, Wageningen, The Netherlands).

Total aggressive behavior was calculated by adding the frequency of aggressive behaviors (lateral attack + biting the intruder's body + aggressive attitude + aggressive cleaning) and the duration of aggressive behaviors (aggressive behavior; adapted from De Almeida et al. 2008).

Lactating rats were divided into the following experimental groups: (1) no social instigation and no aggressive behavior (NI + NA; the acrylic tube was placed empty, without the stimulus rat, in the resident's box, and the rats were not subjected to maternal aggressive behavior, (2) social instigation but no aggressive behavior (I + NA; the acrylic tube was placed in the resident's box with the stimulus rat, and the rats were not subjected to maternal aggressive behavior, (3) no social instigation but aggressive behavior (NI + A; the acrylic tube was placed empty, without the stimulus rat, in the resident's box, and the 
rats were subjected to maternal aggressive behavior, and (4) social instigation and aggressive behavior (I $+\mathrm{A}$; the acrylic tube was placed in the resident's box with the stimulus rat, and the rats were subjected to maternal aggressive behavior.

\section{Male aggressive behavior}

Five minutes after the end of social instigation, adult male rats were subjected to the presence of a male intruder, and their behavior was recorded for 10 min. Given that males did not have a baseline level of aggressiveness, assessing their behavioral repertoire was not possible because they did not show aggressive behaviors against the intruder. The males were divided into the same groups as the lactating females.

\section{Hormone concentrations}

Ten minutes after the end of aggressive behavior or $25 \mathrm{~min}$ after social instigation, on PPD 5, the lactating dams were decapitated, and their blood was collected and placed in previously heparinized tubes. The males were also decapitated after the same interventions. The samples were centrifuged at $4^{\circ} \mathrm{C}(15 \mathrm{~min}$ at $1,500 \mathrm{rpm})$, and the plasma was separated and stored at $-20^{\circ} \mathrm{C}$. Corticosterone was previously extracted from the plasma with ethanol and then resuspended in phosphate buffer for the radioimmunoassay, which used a standard and specific antibody purchased from Sigma (St. Louis, MO, USA) and tritiated corticosterone purchased from Amersham (Pistataway, NJ, USA). Free and bound fractions were separated using dextran-coated charcoal $(0.5 / 0.05 \%)$. The oxytocin that had been previously extracted from the plasma using acetone and ether was resuspended in phosphate buffer for the radioimmunoassay. The oxytocin-specific antibody raised in rabbits and the iodinated hormone were kindly provided by Dr. Mariana Morris (Wright State University, San Antonio, TX, USA) and Prof. Dr. José Antunes Rodrigues (School of Medicine of Ribeirão Preto-USP, Brazil), respectively. The reference standard (OT-8152) was purchased from Bachen- Peninsula Laboratories (San Carlos, CA, USA). The plasma concentrations of prolactin were determined by double-antibody radioimmunoassay using a set of reagents obtained from the National Hormone and Peptide Program (Harbor-UCLA, Torrance, CA, USA). Rat PRL-RP ${ }_{3}$ was used as the reference preparation. The hormone was iodinated and purified at Dr. Celso Rodrigues Franci's laboratory (School of Medicine of Ribeirão Preto-USP, Brazil). The anti-gamma globulin used for precipitation of the reaction in prolactin and oxytocin assays was produced in sheep by Dr. Celso Rodrigues Franci (School of Medicine of Ribeirão Preto-USP, Brazil). The plasma concentrations of progesterone were determined by radioimmunoassay using sets of commercially available reagents (Diagnostic System Laboratories, Webster, TX, USA). The samples were dosed in the same assay as each hormone, and the intraassay error was $4.5 \%$ for oxytocin, $3.5 \%$ for prolactin, $5 \%$ for corticosterone, and $3.5 \%$ for progesterone. The minimum detection limits were $0.4 \mathrm{ng} / \mathrm{ml}$ for oxytocin, $0.2 \mathrm{ng} / \mathrm{ml}$ for prolactin, $2.0 \mathrm{ng} / \mathrm{ml}$ for corticosterone, and $0.3 \mathrm{ng} / \mathrm{ml}$ for progesterone. The hormones were dosed by Dr. Celso R. Franci at laboratory of School of Medicine of Ribeirão Preto-USP, Brazil.

\section{Statistical analysis}

The results are expressed as mean $\pm S E M$. The results of the hormone concentrations in the four experimental groups (NI + NA, I + NA, NI + A, and I $+\mathrm{A}$ ) were assessed using one-way analysis of variance (ANOVA). When the difference was statistically significant, with $p<.05$, the Newman-Keuls test was used as a post hoc analysis. The aggressive behaviors of female rats in both groups subjected to the aggressive behavior test $(\mathrm{NI}+\mathrm{A}$ and $\mathrm{I}+\mathrm{A})$ were analyzed using Student's $t$-test. With respect to non-aggressive motor behaviors, the results for all groups were compared with each other using ANOVA, followed by the Newman-Keuls post hoc test when the difference was statistically significant.

\section{Results}

\section{Lactating rats}

Lactating rats in the NI + A group showed lower plasma corticosterone levels $(p=.01$; Figure 2A) compared with lactating rats in the NI + NA group (control group). Socially instigated lactating rats subjected to aggressive confrontation had reduced corticosterone levels $(p=.01$; Figure 2A) compared with lactating rats in the NI + NA group. Rats exposed only to aggressive behavior (NI + A group) showed lower plasma oxytocin levels $(p=.03$; Figure 2B) compared with the control group. Female rats in the $\mathrm{NI}+$ A group had lower plasma prolactin levels $(p=$ .01 ; Figure 2C), and female rats in the $\mathrm{I}+\mathrm{A}$ group ( $p$ $=.01$; Figure $2 \mathrm{C}$ ) also showed lower levels compared with the control group. Aggressive confrontation alone $(\mathrm{NI}+\mathrm{A}$ group) reduced progesterone levels $(p=.02$; Figure 2D) compared with the control group.

Overall aggressiveness was not statistically different between the $\mathrm{NI}+\mathrm{A}$ and $\mathrm{I}+\mathrm{A}$ groups $\left(t_{19}=\right.$ $.31 ; p=.7$; Figure 3 ). With respect to non-aggressive behaviors, the rats subjected only to social instigation (I + NA group) reduced their total walking time ( $p=.007$; Table 1) compared with rats in the I + A group. This same group (I + NA) also reduced total walking time ( $p$ $=.007$; Table 1) compared with the NI + A group. Rats in the $\mathrm{I}+\mathrm{A}$ group increased their total walking time ( $p$ $=.007$; Table 1) compared with the control group, and 


\section{Hormone Measurements in Lactating Female Rats}

A

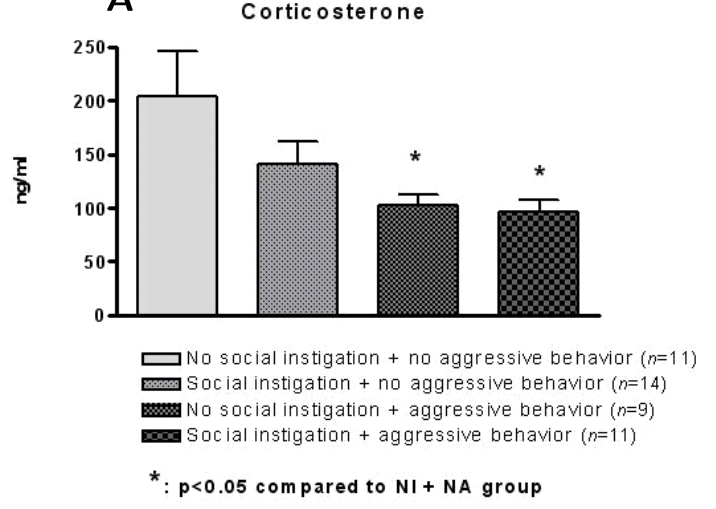

C

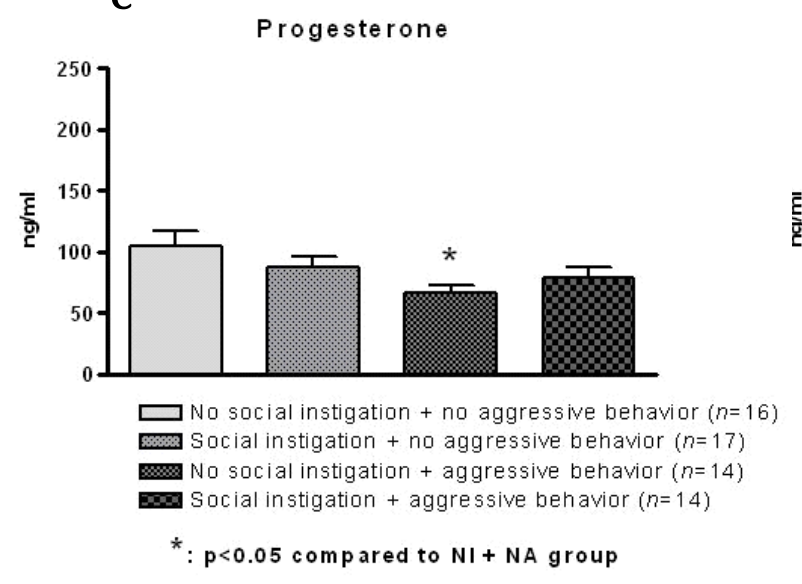

B Oxytocin

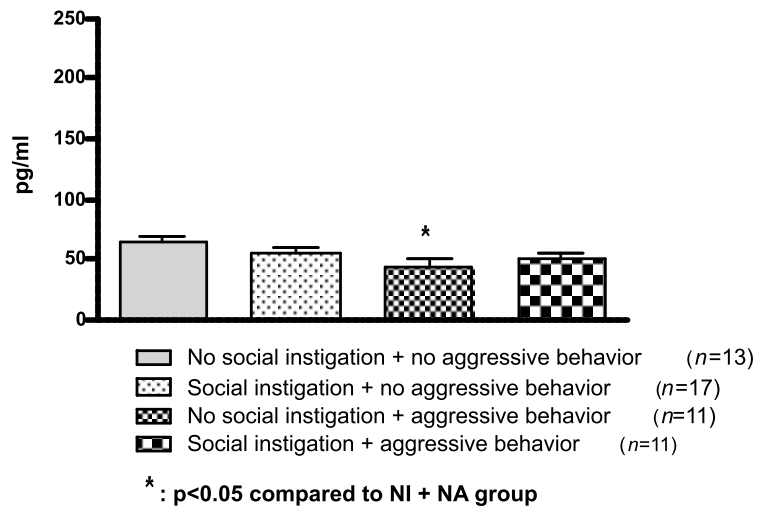

D

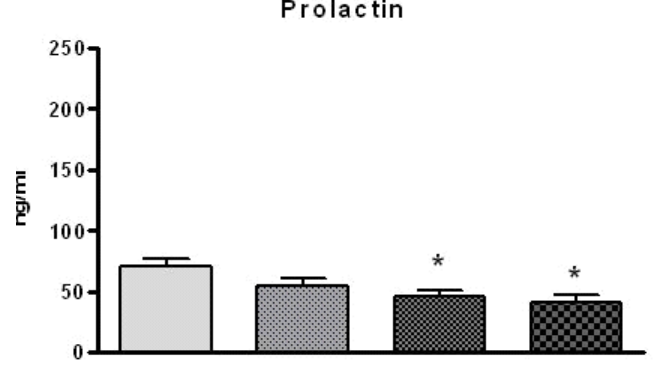

$\square$ No social instigation + no aggressive behavior $(n=12)$

Social instigation + no aggressive behavior $(n=16)$

No social instigation + aggressive behavior $(n=10)$

Social instigation + aggres sive behavior $(n=11)$

* $:$ p $<0.05$ compared to NI + NA group

Figure 2. Effects of social instigation and aggressive behavior on plasma corticosterone (A), oxytocin (B), progesterone (C), and prolactin (D) levels in lactating rats on postpartum day 5 in the presence of pups 10 min after the behavioral test.

female rats subjected only to aggressive behavior (NI + A group) also increased their total walking time ( $p=$ .007; Table 1) compared with the control group. Rats in the $\mathrm{NI}+$ A group reduced the interaction time with their pups $(p=.01$; Table 1$)$ compared with the control group, and rats in the $\mathrm{I}+\mathrm{A}$ group also reduced the interaction time with their pups ( $p=.01$; Table 1) compared with the control group. Self-grooming lasted longer in rats in the I + NA group $(p=.001$; Table 1$)$ compared with the $\mathrm{I}+\mathrm{NA}$ group. The duration of grooming in rats in the I + NA group also increased $(p=.001$; Table 1$)$ compared with the control group and increased in rats in the NI + A group ( $p=.001$; Table 1) compared with the group of rats subjected only to aggressive behavior. Rearing did not yield statistically significant differences when the groups were compared with each other $(F[3,41]=$ $.32 ; p=.80 ;$ Table 1$)$.
Adult male rats

Male rats subjected only to confrontation with an intruder (NI + A group) increased their corticosterone levels $(p=.006$; Figure 4A) compared with the control group (NI + NA group). Social instigation alone (I + NA group) also increased corticosterone levels $(p=.006$; Figure 4A) compared with the control group. Rats in the $\mathrm{I}+\mathrm{A}$ group reduced their corticosterone levels $(p=.006$; Figure $4 \mathrm{~A})$ compared with the $\mathrm{NI}+$ A group, and rats in the I + A group also reduced their corticosterone levels $(p=.006$; Figure 4A) compared with the I + NA group. The results showed increased plasma corticosterone in males that were instigated. Plasma testosterone levels did not show statistically significant differences when the groups were compared with each other $(F[3,36]$ $=1.91 ; p=.1$; Figure 4B). 
Table 1. Duration (in seconds) of non-aggressive behaviors in lactating rats submitted or non to social instigation

\begin{tabular}{|c|c|c|c|c|}
\hline \multirow{2}{*}{ Behaviors } & \multicolumn{4}{|c|}{ Experimentals Groups } \\
\hline & $\mathrm{NI}+\mathrm{NA}(n=11)$ & $\mathrm{I}+\mathrm{NA}(n=14)$ & $\mathrm{NI}+\mathrm{A}(n=9)$ & $\mathrm{I}+\mathrm{A}(n=11)$ \\
\hline Walking & $106.8 \pm 24.59^{\mathrm{a}}$ & $98.75 \pm 22.62^{\mathrm{a}}$ & $178.6 \pm 14.08$ & $182.3 \pm 17.33$ \\
\hline Pup care & $191.9 \pm 65.62$ & $106.1 \pm 46.68$ & $2.31 \pm 1.55^{\mathrm{b}}$ & $3.03 \pm 1.90^{\mathrm{b}}$ \\
\hline Rearing & $39.97 \pm 16.20$ & $40.32 \pm 18.20$ & $22.79 \pm 5.55$ & $29.23 \pm 7.32$ \\
\hline Grooming & $49.58 \pm 15.56$ & $139.6 \pm 19.90^{c}$ & $60.07 \pm 13.59$ & $44.66 \pm 7.70$ \\
\hline
\end{tabular}

Data expressed in mean \pm SEM: ${ }^{\mathrm{a}}: \mathrm{p}<.05$, compared to I + A and NI + A groups; ${ }^{\mathbf{b}}: \mathrm{p}<.05$, compared to NI + NA group; ${ }^{\mathbf{c}}: \mathrm{p}<$ .01 , compared to I + A, NI + NA and NI + A groups

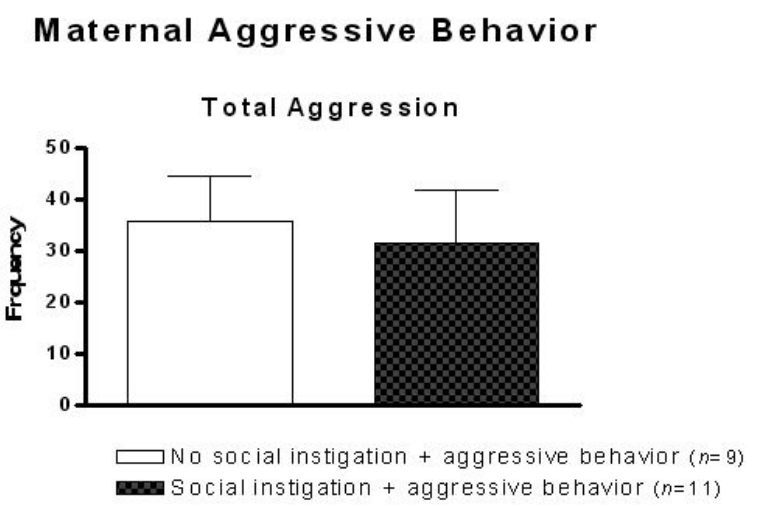

Figure 3. Effects of social instigation on aggressive behavior in lactating rats on postpartum day 5 in the presence of pups.

\section{Discussion}

The experiments revealed that lactating rats subjected to social instigation or aggressive confrontation in the presence of their pups showed lower plasma corticosterone levels, and this response was also valid when oxytocin, prolactin, and progesterone levels were assessed. The present study is the first to assess the neuroendocrine response of lactating rats and socially instigated male rats. Previous studies demonstrated that lactating rats have an attenuated HPA axis response, reducing plasma corticosterone levels in response to both physical and emotional stressors (Lescoat \& Maniey, 1976; Lightman \& Young, 1987, 1989; Lightman et al., 2001; Myers et al., 1975; Neumann et al., 1998; Thoman et al., 1970; Stern \& Levine, 1972; Stern et al., 1973; Smotherman et al., 1976; Walker et al., 1992, 1995; Windle et al., 1997), but few studies have used the maternal defense test or residentintruder test to assess the stress responses of lactating rats (Deschamps, Woodside, \& Walker, 2003; Neumann et al., 2001; Neumann, 2003). Our experiments showed that
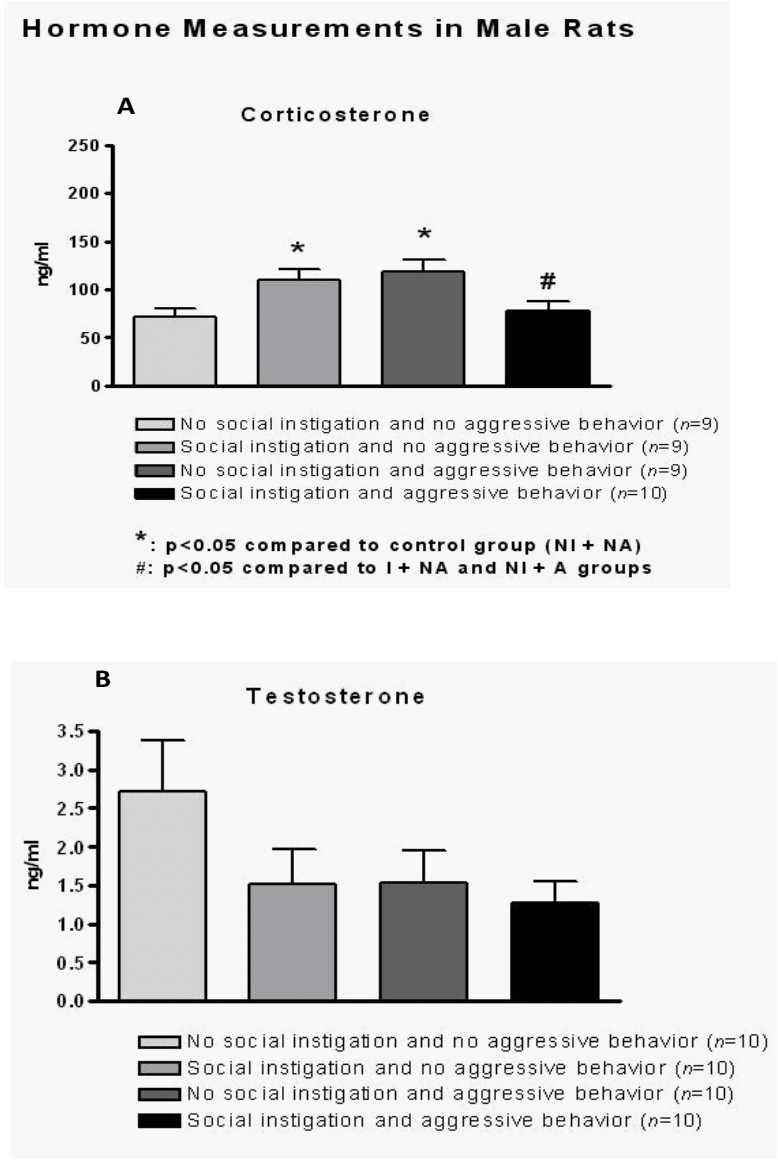

Figure 4. Effects of social instigation and aggressive behavior on plasma corticosterone (A) and testosterone (B) levels in adult male rats.

social instigation followed by aggressive behavior can be regarded as an acute emotional stressor, similar to the social conflict paradigm, that likely lowers plasma corticosterone levels (Neumann et al., 2001).

Our results indicate that socially instigated female rats that exhibit aggressive behavior reduced their corticosterone levels compared with the NI + NA group 
(control group). The presence of an intruder lowered corticosterone levels, which was observed in the NI + A group; however, social instigation alone did not alter corticosterone levels, with social instigation tending to lower corticosterone levels, which was observed in the I + NA group. Thus, variations in corticosterone levels do not apparently depend on the frequency and duration of aggressive behavior exhibited by lactating rats (Figure 3). The most important factor was the presence of the intruder. The results indicate that social instigation per se did not change plasma corticosterone levels in lactating female rats. Using the present experimental protocol, we may only infer that the protected exposition of the male was not sufficient to change HPA axis activity in the lactating mother. The restricted mobility of the SM and its inability to reach the pups could be related to this result.

Lactation may interfere with the attenuation of the HPA axis. Corticosterone secretion increases in virgin (non-lactating) rats after the resident-intruder test (Deschamps et al., 2003). Basal corticosterone levels were high in lactating rats in the control group compared with virgin (non-lactating) rats (Fischer, Patchev, Hellbach, Hassan, \& Almeida, 1995; Lightman et al., 2001). In women, basal cortisol is also high among breastfeeding mothers compared with menstruating women in the eighth week after childbirth (Kammerer, Adams, Castelberg, \& Glover, 2002). According to Stern and Voogt (1973), the stress response of the HPA axis during lactation overlaps with an elevated baseline level of HPA axis activity. The stress response in lactating rats, in which a reduction in plasma corticosterone levels occurs, could be attributable to a decrease in the ACTH response to stressful situations as a result of lower $\mathrm{CRH}$ production and consequently lower release by the pPVN (Brunton et al., 2008). With regard to baseline levels in lactating rats, in which plasma corticosterone levels are elevated, another contributing factor to higher baseline activity of the HPA axis is the continuous presence of the pups. This was demonstrated in experiments in which ACTH and corticosterone levels began to decrease when pups were removed from their mothers for $3.5 \mathrm{~h}$ (Fischer et al., 1995; Walker et al., 1992). Pup retrieval after separation from the dams, which quickly began to care for their offspring, stimulated maternal ACTH secretion (Walker et al., 1992). Therefore, higher baseline activity of the HPA axis is driven by suckling (Brunton et al., 2008), and suckling is an important neuroendocrine stimulus that also increases prolactin and oxytocin secretion, which is essential for milk production (Deschamps et al., 2003; Walker et al., 1992).

With regard to aggressiveness, social instigation did not increase the aggressive behavior of lactating rats, probably because of the large variability among individuals in the same group. Similar effects were also found by Padovan and Guimarães (2004), and a larger number of animals may be necessary to assess aggressiveness in lactating rats, especially when considering the previous study by Veiga et al. (2011), in which aggressive behavior increased after social instigation when a larger number of experimental animals was used. As expected, the actual presence of the intruder decreased pup-directed behaviors, in which pup-directed behaviors decrease while the mother is performing behaviors against the intruder. Thus, when the intruder is in the nest area, the focus of the mother is on the potential danger to the pups.

With regard to the corticosterone levels obtained for male rats, both social instigation and the presence of the intruder increased plasma corticosterone levels after the resident-intruder test compared with males which had no intervention. Surprisingly, the presence of the intruder decreased corticosterone compared with males that were not exposed to the intruder. Importantly, in the present study, the presence of the intruder did not induce aggressive behaviors by the resident male. This result is not consistent with other studies that described high levels of aggressiveness in resident males. Indeed, a single episode of social stress using the resident-intruder test has been reported to increase corticosterone levels in male rats (Haller et al., 1995; Hucklebridge \& Nowell, 1974; Koolhaas et al., 1997; Miczek et al., 1999; Wotjak et al., 1996; Zayan, 1991). In male rodents, social conflict events, such as social defense, have also been widely acknowledged as acute or chronic emotional stressors (Haller et al., 1995; Neumann et al., 2001; Wotjak et al., 1996; Raab et al., 1986). The differences in age and rat strain could explain this discrepancy. Nevertheless, with the reduction in plasma corticosterone levels in males that were exposed to a male intruder compared with males that were not exposed to the intruder, regardless of social instigation, should be addressed in future experiments.

Plasma oxytocin levels decreased in female rats subjected only to aggressive behavior (NI + A group) compared with the control group. Carter and Lightman (1987) found that lactating rats on PPD 6 tended to lower their oxytocin levels after being subjected to acute immobilization stress. Other studies also described this reduction in circulating levels of oxytocin in lactating rats subjected to a stressful stimulus compared with non-lactating rats (Higuchi, Honda, Takano, \& Negoro, 1988; Lightman \& Young, 1989; Neumann, 2003).

Prolactin is also activated in response to physical and emotional stressors (Neill, 1970; Seggie \& Brown, 1975). Our results showed that socially instigated female rats with aggressive behavior had lower prolactin levels, but notably, this reduction also occurred in the group of rats subjected only to aggressive behavior (NI $+\mathrm{A}$ group). Previous studies also demonstrated low prolactin levels in lactating rats after exposure to stress (Banky, Nagy, \& Halasz, 1994; Higuchi, Negoro, \& Arita, 1989; 
Higuchi, Honda, Takano, \& Negoro, 1992; Kehoe, Janik, \& Callahan, 1992; Walker et al., 1992) and also after the maternal defense test (Neumann et al., 2001). Thus, our results concur with the data in the literature.

With regard to plasma progesterone, rats subjected only to aggressive behavior (NI + A group) had lower levels of this hormone compared with the control group. This reduction might partially contribute to the attenuation of the HPA axis response (Lightman et al., 2001). Our results corroborate those in the literature. Lightman et al. (2001) showed that progesterone induces hyporesponsiveness of the HPA axis in lactating rats. After 11 day treatment with estradiol implants and daily injections of progesterone in virgin ovariectomized rats, 3 days of withdrawal of progesterone before the test significantly reduced the activation of the HPA axis compared with animals in which progesterone was given continuously.

This reduction in the response of the HPA axis in lactating rats to environmental stimuli could be the result of low secretion of CRH by the pPVN or vasopressin. Previous studies indicated that CRH mRNA expression (Da Costa, Ma, Ingram, Lightman, \& Aguilera, 2001; Lightman \& Young, 1989; Lightman \& Harbuz, 1993; Walker, Tilders, \& Burlet, 2001) decreases in the PVN in response to stress, and so does c-fos (Da Costa et al., 1996; Deschamps et al., 2003; Shanks et al., 1999; Woodside \& Amir, 1997). The sensitivity of the anterior pituitary to CRH or arginine vasopressin (AVP) might also be lower. Studies in lactating ewes showed that plasma ACTH levels did not increase during restraint stress (Tilbrook, Turner, Ibbott, \& Clarke, 2006). The activity of PVN afferents may also be reduced (Da Costa et al., 1996; Da Costa, Kampa, Windle, Ingram, \& Lightman, 1997; Lightman \& Young, 1989; Shanks et al., 1999; Stern \& Voogt, 1973) because brain regions that modulate the processing the information about stressors are poorly activated (Herman, Ostrander, Mueller, \& Figueiredo, 2005). c-fos mRNA expression was shown to be lower in the amygdala, ventral lateral septum, and cingulate cortex (Da Costa et al., 1996).

Under normal circumstances, noradrenergic brainstem afferents (Douglas, Meddle, Toschi, Bosch, \& Neumann, 2005; Flugge, van Kampen, \& Mijnster, 2004; Herman, \& Cullinan, 1997; Herman et al., 2003; Plotsky, Cunningham, \& Widmaier, 1989; Stanford, 1995; Sawchenko \& Swanson, 1982; Sawchenko, Li, \& Ericsson, 2000) stimulate the HPA axis during stressful situations, increasing the synthesis and secretion of CRH and AVP (for review, see Douglas et al., 2005). Therefore, another mechanism that might contribute to a lower response of the HPA axis in lactating rats to environmental stimuli is the reduction in stimulatory noradrenergic afferents to the PVN, which alter the activity of the HPA axis (Lightman et al., 2001; Walker et al., 2004; Douglas et al., 2005; Tu, Lupien, \& Walker, 2005).
The suckling stimulus caused by the pups, or at least to their presence, during breastfeeding plays a key role in the maintenance of an attenuated HPA axis response in lactating rats (Walker et al., 1992), although precise mechanisms have not been well established (Tilbrook et al., 2006). The effect of the presence of pups depends on the relevance of the stressor. In early lactation, a stressor that threatens the pups (intruder male or predator scent) stimulates the maternal HPA axis response only if the pups are present during the stress (Deschamps et al., 2003). The response to the stressor appears to be related to fear behavior of the dams with their pups, and the loss of this response in late lactation could be related to low CRH mRNA expression in the amygdala (Deschamps et al., 2003). In sheep, cortisol the response to emotional stressors decreases during lactation in a more remarkable fashion if the lamb is present and is lower if the lamb can suckle (Tilbrook \& Clarke, 2006; Tilbrook et al., 2006). Lactating women who have recently breastfed had an attenuated HPA axis response to an emotional stressor (Heinrichs et al., 2001; Heinrichs, Neumann, \& Ehlert, 2002).

The attenuation of the HPA axis response in lactating rats to a stressor could be considered crucial to the dam's welfare (Slattery \& Neumann, 2008) so that it can ideally care for its offspring. Studies have shown that reduced hormone secretion in response to stress during lactation is important to prevent excess circulating levels of glucocorticoids, which may affect the normal development of the pups (Altemus, Deuster, Galliven, Carter, \& Gold, 1995; McCormick, Smythe, Sharma, \& Meaney, 1995; Vallee et al., 1997; Weinstock, 2001). In humans, for example, mothers are more susceptible to the development of mood disorders in the postpartum period (Llewellyn, Stowe, \& Nemeroff, 1997; Mastorakos, \& Ilias, 2000; O'Hara \& Swain, 1996; Pedersen, 1999), which can last up to 1 year and significantly affect the newborn infant's development and family unit.

In summary, social instigation and aggressive confrontation significantly reduced hormone levels in lactating rats in the presence of their pups. In adult male rats, an increase in corticosterone secretion was observed, thus confirming that lactation is a relevant factor in determining neuroendocrine responses to stress.

\section{Acknowledgments}

The authors are indebted to CAPES for financial support and Cármen Marilei Gomes for technical assistance.

\section{References}

Agrati, D., Zuluaga, M.J., Fernández-Guasti, A., Meikle, A., \& Ferreira, A. (2008). Maternal condition reduces fear behaviors but not the endocrine response to an emotional threat in virgin female rats. Hormones and Behavior, 53, 232-240. 
Albert, D.J., Jonik, R.H., \& Walsh, M.L. (1992). Hormone-dependent aggression in male and female rats: experiential, hormonal, and neural foundations. Neuroscience and Biobehavioral Reviews, 16, 177-192.

Altemus, M., Deuster, P.A., Galliven, E., Carter, C.S., \& Gold, P.W. (1995). Suppression of hypothalamic-pituitary-adrenal axis responses to stress in lactating women. Journal of Clinical Endocrinology and Metabolism, 80, 2954-2959.

Banky, Z., Nagy, G.M., \& Halasz, B. (1994). Analysis of pituitary prolactin and adrenocortical response to ether, formalin or restraint in lactating rats: rise in corticosterone, but no increase in plasma prolactin levels after exposure to stress. Neuroendocrinology, 59, 63-71.

Brunton, P.J., Russell, J.A., \& Douglas, A.J. (2008). Adaptive responses of the maternal hypothalamic-pituitary-adrenal axis during pregnancy and lactation. Journal of Neuroendocrinology, 20, 764-776.

Carter, D.A., \& Lightman, S.L. (1987). Oxytocin responses to stress in lactating and hyperprolactinemic rats. Neuroendocrinology, 46, 532-537.

Consiglio, A.R., \& Lucion, A.B. (1996). Lesion of hypothalamic paraventricular nucleus and maternal aggressive behavior in female rats. Physiology and Behavior, 59, 591-596.

Consiglio, A.R., \& Bridges, R.S. (2009). Circulating prolactin, MPOA prolactin receptor expression and maternal aggression in lactating rats. Behavioural Brain Research, 197, 97-102.

Da Costa, A.P.C., Wood, S., Ingram, C.D., \& Lightman, S.L. (1996). Region-specific reduction in stress-induced c-fos mRNA expression during pregnancy and lactation. Brain Research, 742, 177-184.

Da Costa, A.P.C., Kampa, R.J., Windle, R.J., Ingram, C.D., \& Lightman, S.L. (1997). Region-specific immediate-early gene expression following the administration of corticotropin-releasing hormone in virgin and lactating rats. Brain Research, 770, 151-162.

Da Costa, A.P., Ma, X., Ingram, C.D., Lightman, S.L., \& Aguilera, G. (2001). Hypothalamic and amygdaloid corticotropin-releasing hormone $(\mathrm{CRH})$ and $\mathrm{CRH}$ receptor-1 mRNA expression in the stress-hyporesponsive late pregnant and early lactating rat. Brain Research Molecular Brain Research, 91, 119-130.

De Almeida, R.M.M., \& Lucion, A.B. (1997). 8-OH-DPAT in the median raphé, dorsal periaqueductal gray and corticomedial amygdala nucleus decreases, but the medial septal area it can increase maternal aggressive behavior in rats. Psychopharmacology, 134, 392-400.

De Almeida, R.M.M., \& Miczek, K.A. (2002). Aggression escalated by social instigation or by discontinuation of reinforcement ("frustration") in mice: inhibition by anpirtoline: a $5-\mathrm{HT}_{1 \mathrm{~B}}$ receptor agonist. Neuropsychopharmacology, 27(2), 171-181.

De Almeida, R.M.M., Benini, Q., Betat, J.S., Hipólide, D.C., Miczek, K.A., \& Svensson, A.I. (2008). Heightened aggression after chronic flunitrazepam in male rats: potential links to cortical and caudateputamen-binding sites. Psychopharmacology, 197, 309-318.

Deschamps, S., Woodside, B., \& Walker, C.D. (2003) Pups presence eliminates the stress hyporesponsiveness of early lactating females to a psychological stress representing a threat to the pups. Journal of Neuroendocrinology, 15, 486-497.

Douglas, A.J., Johnstone, H.A., Wigger, A., Landgraf, R., Russell, J.A., \& Neumann, I.D. (1998). The role of endogenous opioids in neurohypophysial and hypothalamo-pituitary-adrenal axis hormone secretory responses to stress in pregnant rats. Journal of Endocrinology, 158, 285-293.

Douglas, A.J., Meddle, S.L., Toschi, N., Bosch, O.J., \& Neumann, I.D. (2005). Reduced activity of the noradrenergic system in the paraventricular nucleus at the end of pregnancy: implications for stress hyporesponsiveness. Journal of Neuroendocrinology, 17, 40-48.

Erskine, M.S., Barfield, R.J., \& Goldman, B.D. (1978). Intraspecific fighting during late pregnancy and lactation in rats and effects of litter removal. Behavioral Biology, 23, 206-218.

Factor, E.M., Mayer, A.D., \& Rosenblatt, J.S.(1990). Preventing suckling-induced release of oxytocin does not inhibit maternal aggression in lactating rats. Annals of the New York Academy of Sciences, 652, 423-424.

Ferreira, A., Dahlof, L.G., \& Hansen, S. (1987). Olfactory mechanisms in the control of maternal aggression, appetite, and fearfulness: effects of lesions to olfactory receptors, mediodorsal thalamic nucleus, and insular prefrontal cortex. Behavioral Neuroscience, 101, 709-717 (see also p. 746).

Fischer, D., Patchev, V.K., Hellbach, S., Hassan, A.H.S., \& Almeida,
O.F.X. (1995). Lactation as a model of naturally reversible hypercorticalism plasticity in the mechanisms governing hypothalamo-pituitary-adrenocortical activity in rats. Journal of Clinical Investigation, 96, 1208-1215.

Fish, E.W., Faccidomo, S., \& Miczek, K.A. (1999). Aggression heightened by alcohol or social instigation in mice: reduction by the 5-HT receptor agonist CP-94,253. Psychopharmacology, 146, 391-399.

Flugge, G., van Kampen, M., \& Mijnster, M.J. (2004). Perturbations in brain monoamine systems during stress. Cell and Tissue Research, $315,1-14$.

Gamallo, A., Villanua, A., Trancho, G., \& Fraile, A. (1986). Stress adaptation and adrenal activity in isolated and crowded rats. Physiology and Behavior, 36, 217-221.

Haller, J., Barna, I., \& Baranyi, M. (1995). Hormonal and metabolic responses during psychosocial stimulation in aggressive and nonaggressive rats. Psychoneuroendocrinology, 20, 65-74.

Hansen, S. (1989). Medial hypothalamic involvement in maternal aggression of rats. Behavioral Neuroscience, 103, 1035-1046.

Heinrichs, M., Meinlschmidt, G., Neumann, I., Wagner, S., Kirschbaum, C., Ehlert, U., \& Hellhammer, D.H. (2001). Effects of suckling on hypothalamic-pituitary-adrenal axis responses to psychosocial stress in postpartum lactating women. Journal of Clinical Endocrinology and Metabolism, 86, 4798-4804.

Heinrichs, M., Neumann, I., \& Ehlert, U. (2002) Lactation and stress: protective effects of breast-feeding in humans. Stress, 5, 195-203.

Herman, J.P., \& Cullinan, W.E. (1997). Neurocircuitry of stress: central control of the hypothalamo-pituitary-adrenocortical axis. Trends in Neurosciences, 20, 78-84.

Herman, J.P., Figueiredo, H., Mueller, N.K., Ulrich-Lai, Y., Ostrander, M.M., Choi, D.C., \& Cullinan, W.E. (2003). Central mechanisms of stress integration: hierarchical circuitry controlling hypothalamo-pituitary-adrenocortical responsiveness. Frontiers in Neuroendocrinology, 24, 151-180.

Herman, J.P., Ostrander, M.M., Mueller, N.K., \& Figueiredo, H. (2005). Limbic system mechanisms of stress regulation: hypothalamopituitary-adrenocortical axis. Progress in Neuropsychopharmacology and Biological Psychiatry, 29, 1201-1213.

Higuchi, T., Honda, K., Takano, S., \& Negoro, H. (1988). Reduced oxytocin response to osmotic stimulus and immobilization stress in lactating rats. Journal of Endocrinology, 116, 225-230.

Higuchi, T., Negoro, H., \& Arita, J. (1989). Reduced responses of prolactin and catecholamine to stress in the lactating rat. Journal of Endocrinology, 122, 495-498.

Higuchi, T., Honda, K., Takano, S., \& Negoro, H. (1992). Abolition of prolactin surge induced by ovarian steroid hormones in the lactating rat. Neuroendocrinology, 56, 234-239.

Hucklebridge, F.H., \& Nowell, N.W. (1974). Plasma catecholamine response to physical and psychological aspects of fighting in mice. Physiology and Behavior, 13, 35-40.

Johnstone, H.A., Wigger, A., Douglas, A.J., Neumann, I.D., Landgraf, R., Seckl, J.R., \& Russell, J.A. (2000). Attenuation of hypothalamic-pituitary-adrenal axis stress responses in late pregnancy: changes in feedforward and feedback mechanisms. Journal of Neuroendocrinology, 12, 811-822.

Kammerer, M., Adams, D., Castelberg, B.V.B., \& Glover, V. (2002). Pregnant women become insensitive to cold stress. BMC Pregnancy and Childbirth, 2,8 .

Kehoe, L., Janik, J., \& Callahan, P. (1992). Effects of immobilization stress on tuberoinfundibular dopaminergic (TIDA) neuronal activity and prolactin levels in lactating and non-lactating female rats. Life Sciences, 50, 55-63.

Kolunie, J.M., \& Stern, J.M. (1995). Maternal aggression in rats: effects of olfactory bulbectomy, ZnSO4-induced anosmia, and vomeronasal organ removal. Hormones and Behavior, 29, 492-518.

Koolhaas, J.M., Meerlo, P., De Boer, S.F., Strubbe, J.H., \& Bohus, B. (1997). The temporal dynamics of the stress response. Neuroscience and Biobehavioral Reviews, 21, 775-782.

Kudielka, B.M., \& Kirschbaum, C. (2005). Sex differences in HPA axis responses to stress: a review. Biological Psychology, 69, 113-132.

Lagerspetz, K., \& Hautojarvi, S. (1967). The effect of prior aggressive or sexual arousal on subsequent aggressive or sexual reactions in male mice. Scandanavian Journal of Psychology, 8, 1-6.

Lescoat, G., \& Maniey, J. (1976). Lactation and sensitivity to corticotropicaxis to stress. Journal de Physiologie (Paris), 70, 695-708. 
Li, X., Ren, L., Weng, Q., Trisomboon, H., Yamamoto, T., Pan, L.,... Taya, K. (2010). Effects of acute restraint stress on sperm motility and secretion of pituitary, adrenocortical, and gonadal hormones in adult male rats. Journal of Veterinary Medical Science, 72, 1501-1506.

Lightman, S.L., \& Young, W.S., 3rd (1987). Vasopressin, oxytocin, dynorphin, enkephalin and corticotrophin-releasing factor mRNA stimulation in the rat. Journal of Physiology, 394, 23-39.

Lightman, S.L., \& Young, W.S., 3rd (1989). Lactation inhibits stress-mediated secretion of corticosterone and oxytocin and hypothalamic accumulation of corticotropin-releasing factor and enkephalin messenger ribonucleic acids. Endocrinology, 124, 2358-2364.

Lightman, S.L., \& Harbuz, M.S. (1993). Expression of corticotropinreleasing factor mRNA in response to stress. Ciba Foundation Symposium, 172, 173-187.

Lightman, S.L., Windle, R.J., Wood, S.A., Kershaw, Y.M., Shanks, N., \& Ingram, C.D. (2001). Peripartum plasticity within the hypothalamo-pituitary-adrenal axis. Progress in Brain Research, 133, 111-129.

Llewellyn, A.M., Stowe, Z.N., \& Nemeroff, C.B. (1997). Depression during pregnancy and the puerperium. Journal of Clinical Psychiatry, 58 (Suppl. 15), 26-32.

Lonstein, J.S., Simmons, D.A., \& Stern, J.M. (1998). Functions of the caudal periaqueductal gray in lactating rats: kyphosis, lordosis, maternal aggression, and fearfulness. Behavioral Neuroscience, $112,1502-1518$.

Lonstein, J.S., \& Gammie, S.C. (2002). Sensory, hormonal, and neural control of maternal aggression in laboratory rodents. Neuroscience and Biobehavioral Reviews, 26, 869-888.

Lonstein, J.S. (2005). Resolving apparent contradictions concerning the relationships among fear or anxiety and aggression during lactation: theoretical comment on D'Anna, Stevenson, and Gammie (2005). Behavioral Neuroscience, 119, 1165-1168.

Mastorakos, G., \& Ilias, I. (2000). Maternal hypothalamic-pituitaryadrenal axis in pregnancy and the postpartum period: postpartumrelated disorders. Annals of the New York Academy of Sciences, 900, 95-106.

Mayer, A.D., \& Rosenblatt, J.S. (1987). Hormonal factors influence the onset of maternal aggression in laboratory rats. Hormones and Behavior, 21, 253-267.

Mayer, A.D., Monroy, M.A., \& Rosenblatt, J.S. (1990). Prolonged estrogen-progesterone treatment of nonpregnant ovariectomized rats: factors stimulating home-cage and maternal aggression and shortlatency maternal behavior. Hormones and Behavior, 24, 342-364.

McCormick, C.M., Smythe, J.W., Sharma, S., \& Meaney, M.J. (1995). Sex-specific effects of prenatal stress on hypothalamicpituitary-adrenal responses to stress and brain glucocorticoid receptor density in adult rats. Brain Research Developmental Brain Research, 84, 55-61.

Miczek, K.A., Nikulina, E., Kream, R.M., Carter, G., \& Espejo, E.F. (1999). Behavioral sensitization to cocaine after a brief social defeat stress: c-fos expression in the PAG. Psychopharmacology, 141, 225-234.

Mos, J., \& Olivier, B. (1986). RO 15-1788 does not influence postpartum aggression in lactating female rats. Psychopharmacology, 90, 278-280.

Myers, M.M., Denenberg, V.H., Thoman, E., Holloway, W.R., \& Bowerman, D.R. (1975). The effects of litter size on plasma corticosterone and prolactin response to ether stress in the lactating rat. Neuroendocrinology, 19, 54-58.

Neill, J.J.D. (1970). Effects off "stress" on serum prolactin and luteinizing hormone levels during the estrous cycle of the rat. Endocrinology, 87, 1192-1197.

Neumann, I.D., Johnstone, H.A., Hatzinger, M., Liebsch, G., Shipston, M., Russell, J.A., Landgraf, R., \& Douglas, A.J. (1998). Attenuated neuroendocrine responses to emotional and physical stressors in pregnant rats involve adenohypophysial changes. Journal of Physiology, 508, 289-300.

Neumann, I.D., Toschi, N., Ohl, F., Torner, L., \& Kromer, S.A. (2001). Maternal defence as an emotional stressor in female rats: correlation of neuroendocrine and behavioural parameters and involvement of brain oxytocin. European Journal of Neuroscience, 13, 1016-1024.

Neumann, I.D. (2003). Brain mechanisms underlying emotional alterations in the peripartum period in rats. Depression and Anxiety, $17,111-121$.

Numan, M., \& Insel, T.R. (2003). The neurobiology of parental behavior. New York: Springer-Verlag.
O'Hara, M., \& Swain, A. (1996). Rates and risks of postpartum depression: a meta-analysis. International Review of Psychiatry, 8, 37-54.

Padovan, C.M., \& Guimarães, F.S. (2004). Antidepressant-like effects of NMDA-receptor antagonist injected into the dorsal hippocampus of rats. Pharmacology, Biochemistry and Behavior, 77, 15-19.

Pedersen, C.A. (1999). Postpartum mood and anxiety disorders: a guide for the nonpsychiatric clinician with an aside on thyroid associations with postpartum mood. Thyroid, 9, 691-697.

Plotsky, P.M., Cunningham, E.T., Jr., \& Widmaier, E.P. (1989). Catecholaminergic modulation of corticotropin-releasing factor and adrenocorticotropin secretion. Endocrine Reviews, 10, 437-458.

Potegal, M. (1991). Attack priming and satiation in female golden hamsters: tests of some alternatives to the aggression arousal interpretation. Aggressive Behavior, 17, 327-335.

Potegal, M., \& Tenbrink, L. (1984). Behavior of attack-primed and attack-satiated female golden hamsters (Mesocricetus auratus). Journal of Comparative Psychology, 98, 66-75.

Raab, A., Dantzer, R., Michaud, B., Mormede, P., Taghzouti, K., Simon, H., \& Le Moal, M. (1986). Behavioural, physiological and immunological consequences of social status and aggression in chronically coexisting resident-intruder dyads of male rats. Physiology and Behavior, 36, 223-228.

Sawchenko, P.E., \& Swanson, L.W. (1982). The organization of noradrenergic pathways from the brainstem to the paraventricular and supraoptic nuclei in the rat. Brain Research, 257, 275-325.

Sawchenko, P.E., Li, H.Y., \& Ericsson, A. (2000). Circuits and mechanisms governing hypothalamic responses to stress: a tale of two paradigms. Progress in Brain Research, 122, 61-78.

Seggie, J.A., \& Brown, G.M. (1975). Stress response patterns of plasma corticosterone, prolactin, and growth hormone in the rat, following handling or exposure to novel environment. Canadian Journal of Physiology and Pharmacology, 53, 629-637.

Shanks, N., Windle, R.J., Perks, P., Wood, S., Ingram, C.D., \& Lightman, S.L. (1999). The hypothalamic-pituitary-adrenal axis response to endotoxin is attenuated during lactation. Journal of Neuroendocrinology, 11, 857-865.

Slattery, D.A., \& Neumann, I.D. (2008). No stress please! Mechanisms of stress hyporesponsiveness of the maternal brain. Journal of Physiology, 586, 377-385.

Smotherman, W.P., Wiener, S.G., Mendoza, S.P., \& Levine, S. (1976). Pituitary-adrenal responsiveness of rat mothers to noxious stimuli and stimuli produced by pups. Ciba Foundation Symposium, 45, 5-25.

Stanford, S.C. (1995). Central noradrenergic neurones and stress. Pharmacology and Therapeutics, 68, 297-342.

Stern, J.M., \& Levine, S. (1972). Pituitary-adrenal activity in the postpartum rat in the absence of suckling stimulation. Hormones and Behavior, 3, 237-246.

Stern, J.M., Goldman, L., \& Levine, S. (1973). Pituitary-adrenal responsiveness during lactation in rats. Neuroendocrinology, 12, 179-191.

Stern, J.M., \& Voogt, J.L. (1973). Comparison of plasma corticosterone and prolactin levels in cycling and lactating rats. Neuroendocrinology, 13, 173-181.

Thoman, E.B., Conner, R.L., \& Levine, S. (1970). Lactation suppresses adrenal corticosteroid activity and aggressiveness in rats. Journal of Comparative and Physiological Psychology, 70, 364-369.

Tilbrook, A.J., \& Clarke, I.J. (2006). Neuroendocrine mechanisms of innate states of attenuated responsiveness of the hypothalamopituitary adrenal axis to stress. Frontiers in Neuroendocrinology, 27, 285-307.

Tilbrook, A.J., Turner, A.I., Ibbott, M.D., \& Clarke, I.J. (2006). Activation of the hypothalamo-pituitary-adrenal axis by isolation and restraint stress during lactation in ewes: effect of the presence of the lamb and suckling, Endocrinology, 147, 3501-3509.

Toufexis, D.J., \& Walker, C.D. (1996). Noradrenergic facilitation of the adrenocorticotropin response to stress is absent during lactation in the rat. Brain Research, 737, 71-77.

Tu, M.T., Lupien, S.J., \& Walker, C.D. (2005). Measuring stress responses in postpartum mothers: perspectives from studies in human and animal populations. Stress, 8 (1), 19-34.

Vallee, M., Mayo, W., Dellu, F., Le Moal, M., Simon, H., \& Maccari, S. (1997). Prenatal stress induces high anxiety and postnatal handling induces low anxiety in adult offspring: correlation with stress-induced corticosterone secretion. Journal of Neuroscience, $17,2626-2636$. 
Veenema, A.H., Torner, L., Blume, A., Beiderbeck, D.I., \& Neumann, I.D. (2007). Low inborn anxiety correlates with high intermale aggression: link to ACTH response and neuronal activation of the hypothalamic paraventricular nucleus. Hormones and Behavior, 51, 11-19.

Veiga, CP., Miczek, K.A., Lucion, A.B., \& De Almeida, R.M.M. (2007). Effect of 5-HT1B receptor agonists injected into the prefrontal cortex on maternal aggression in rats. Brazilian Journal of Medical and Biological Research, 40, 825-830.

Veiga, C.P., Miczek, K.A., Lucion, A.B., \& De Almeida, R.M.M. (2011). Social instigation and aggression in postpartum female rats: role of 5-HT1A and 5-HT1B receptors in the dorsal raphé nucleus and prefrontal cortex. Psychopharmacology, 213, 475-487

Walker, C.D., Lightman, S.L., Steele, M.K., \& Dallman, M.F. (1992). Suckling is a persistent stimulus to the adrenocortical system of the rat. Endocrinology, 130, 115-125.

Walker, C.D., Trottier, G., Rochford, J., \& Lavallee, D. (1995). Dissociation between behavioral and hormonal responses to the forced swim stress in lactating rats. Journal of Neuroendocrinology, 7, 615-622.

Walker, C.D., Tilders, F.J., \& Burlet, A. (2001). Increased colocalization of corticotropin-releasing factor and arginine vasopressin in paraventricular neurones of the hypothalamus in lactating rats: evidence from immunotargeted lesions and immunohistochemistry. Journal of Neuroendocrinology, 13, 74-85.

Walker, C.D., Deschamps, S., Proulx, K., Tu, M., Salzman, C., Woodside, B., ...Richard, D. (2004). Mother to infant or infant to mother? Reciprocal regulation of responsiveness to stress in rodents and the implications for humans. Journal of Psychiatry and Neuroscience, 29, 364-382.

Weinstock, M. (2001). Alterations induced by gestational stress in brain morphology and behaviour of the offspring. Progress in Neurobiology, 65, 427-451.

Windle, R.J., Wood, S., Shanks, N., Perks, P., Conde, G.L., da Costa, A.P.C., Ingram, C.D., \& Lightman, S.L. (1997). Endocrine and behavioural responses to noise stress: comparison of virgin and lactating female rats during non-disrupted maternal activity. Journal of Neuroendocrinology, 9, 407-414.

Woodside, B., \& Amir, S. (1997). Lactation reduces Fos induction in the paraventricular and supraoptic nuclei of the hypothalamus after urethane administration in rats. Brain Research, 752, 319-323.

Wotjak, C.T., Kubota, M., Liebsch, G., Montkowski, A., Holsboer, F., Neumann, I., \& Landgraf, R. (1996). Release of vasopressin within the rat paraventricular nucleus in response to emotional stress: a novel mechanism of regulating adrenocorticotropic hormone secretion? Journal of Neuroscience, 16, 7725-7732.

Zayan, R. (1991). The specificity of social stress. Behavioural Processes, 25, 81-93. 